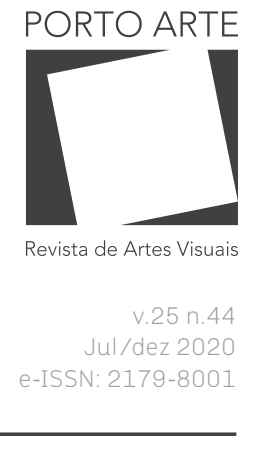

\title{
Notas sobre a abstração informal na historiografia da Arte no Brasil.
}

Notes on informal abstraction in Brazilian Art historiography

\section{Mayã Gonçalves Fernandes}

ORCID: 0000-0002-9600-6786

Universidade de Brasília, Brasil

\section{Vera Pugliese}

ORCID: 0000-0001-8101-4751

Universidade de Brasília, Brasil

\section{Resumo}

Este artigo tem como objetivo analisar elementos da inscrição do abstracionismo informal na tensão entre o moderno e o contemporâneo na historiografia da arte no Brasil. Embora parte dessa fortuna crítica identifique na abstração uma persistência por parte de alguns artistas na utilização do paradigma moderno para responder a questões contemporâneas, outros artistas como Leda Catunda, Luiz Aquila e Tatiana Blass parecem aludir ao abstracionismo informal, experimentando-se e incorporando processos abstratos em outras linguagens e poéticas. Deste modo, propomos contribuir para a necessária revisão do processo de historicização do abstracionismo no Brasil a partir da reflexão sobre algumas obras de artistas participantes da exposição "Oito décadas da abstração informal", realizada em 2018 no MASP, a fim de problematizar noções sobre o abstrato na contemporaneidade.

\section{Palavras-chave}

Abstração na Arte Contemporânea. Abstracionismo informal. Historiografia da Arte Brasileira. Tensão crítica.

1- Este texto é resultado de pesquisa com Fomento do $\mathrm{CNPq}$ e de pesquisa de pós-doutorado com bolsa da FAP-DF realizada na École des Hautes Études en Sciences Sociales - EHESS, Paris, realizado por Prof $^{a} \mathrm{Dr}^{\mathrm{a}}$ Vera Pugliese e pela pesquisa desenvolvida durante o doutorado com bolsa CAPES da doutoranda em Artes Visuais pela Universidade de Brasília, Mayã Fernandes.

\begin{abstract}
This article aims to analyze the elements of the informal abstraction inscription in the tension between the modern and the contemporary in Brazilian art historiography. Although part of the critical fortune identifies the persistence of using a modern paradigm in abstraction in order to answer to contemporary questions, other artists such as Leda Catunda, Luiz Aquila and Tatiana Blass allude to informal abstractionism, experimenting with it and incorporating abstract processes in other languages and poetics. Therefore, we propose a contribution to the revision of the historicization process of abstractionism in Brazil investigating aspects of the exhibition "Eight decades of informal abstraction", held in 2018 at MASP, in order to call into question the main notions about the abstract in a contemporary approach.
\end{abstract}

Keywords

Contemporary Art Abstraction. Informal abstraction. Art Historiography in Brazil. Critical shift. 


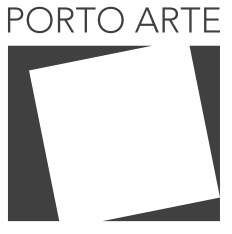

Revista de Artes Visuais

v $25 n .44$

Jul/dez 2020 e-ISSN: 2179-8001

Presenciamos, há mais de duas décadas, a discussão dos objetos e fronteiras da história da arte diante de quadros de classificações e conceitos-chave, bem como métodos estabelecidos. A fertilidade da tensão interpretativa gerada por esse debate impõe rever objetos de investigação e procedimentos teórico-metodológicos que levem em conta a complexidade de diferentes meios culturais e suas relações, bem como trânsitos de modelos teóricos e artísticos. Analogamente, este movimento de revisão requer reexaminar bases epistêmicas da historiografia da arte, questionar hegemonias e problematizar bases conceituais de certos consensos que parecem se cristalizar no próprio léxico dessa disciplina.

A abstração é um desses conceitos, seja em termos de classificações pertinentes ao abstracionismo novecentista - construtivo, geométrico, expressivo, informal, onírico, sensível, gestual, sígnico, matérico - , seja acerca de uma concepção mais compreensiva da abstração distinta da europeia-estadunidense (PUGLIESE, 2018, p. 3857). Considerando o contexto brasileiro, existem ainda outras questões ligadas ao modernismo e a necessária atenção à relação dos âmbitos local/nacional e questões institucionais.

A problematização da figuração e a emergência e desenvolvimento do abstracionismo europeu ocupam lugar de destaque na produção artística do século XX, no Ocidente. A busca pelo invisível aos olhos e pelo objeto presente na interioridade do sujeito marcaram as vanguardas abstracionistas e configuraram-se, durante as primeiras décadas do século $\mathrm{XX}$, a vontade de experimentar e alcançar o que a representação da realidade fenomênica não consegue exprimir. Eliane Escoubas (2006, p. 164) relata que existe um desejo de ver sendo que o quadro propicia outra dimensão do ato de ver.

A abstração moderna surge no interior das primeiras vanguardas novecentistas, tendo como marco as primeiras pinturas de Wassily Kandinsky em Munique, na virada para os anos 1910, mas também as experimentações de Franz Kupka e Robert Delaunay em Paris. Entre outros reconhecidos arautos da abstração surgem, nos anos subsequentes, artistas como Piet Mondrian, em Paris e Amsterdã, em 1914, contemporaneamente a Kazimir Malevitch, em Moscou. Como Dora Vallier (1980, p. 9) assinalou, a arte abstrata rapidamente se disseminou pela Europa no início do século XX, sendo em grande medida tributária de problematizações da ordem plástica anterior e criação de elementos, vocabulários e sintaxes derivados do Expressionismo alemão e do Fauvismo e Cubismo franceses. Os pintores Kandinsky, Mondrian e Malevitch chegam à desejada abstração por caminhos diferentes, o que gerou compreensões diversas do que seria o abstrato ${ }^{1}$.

$\mathrm{Na}$ história da arte, entende-se recorrentemente que a abstração se manifestou, desde os anos 1910, grosso modo, por meio de duas tendências dominantes, a formal e a expressiva, cada uma agrupando artistas e movimentos, mas também gerando outras tendências mais específicas. Depreendemos da abstração formal, ou seja, daquela que valoriza nos elementos plásticos e fatores composicionais na constituição da obra, noções como construção, clareza, ordem, racionalidade, associando-se frequentemente à abstração geométrica. Já a abstração expressiva, que valoriza a subjetividade da

\footnotetext{
1- Hubert Damisch (2009, 133-135) realiza uma separação metodológica entre o abstrato e o abstracionismo. Para ele, o abstracionismo está relacionado às vanguardas do período moderno, enquanto o abstrato está presente na história da arte antes e depois destas vanguardas. Desse modo, assumimos o conceito de abstrato damischiano.
} 


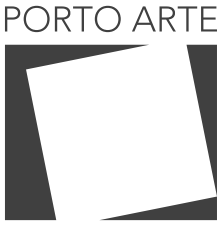

Revista de Artes Visuais

v. 25 ก. 44

$\mathrm{Jul} / \mathrm{dez} 2020$ e-ISSN: 2179-8001

criação artística, envolve amiúde noções como intuição, força expressiva do gesto, da matéria, de signos, direcionando elementos plásticos e fatores composicionais para evocações da interioridade do artista. É consensual nessa disciplina reconhecer seus elementos na base da abstração onírica que começa a despontar em meados dos anos 1920, muitas vezes ligada ao Dada e ao Surrealismo. Assim, essa polarização amplamente divulgada na fortuna crítica do abstracionismo moderno se manifestaria como, de um lado, o abstracionismo geométrico - ligado à tão reivindicada vontade construtiva, no Brasil -, que buscava a alusão ou a transposição da realidade fenomênica ou de suas estruturas invisíveis por meio da matemática e da geometria, ou como disse Giulio Carlo Argan (1993, p. 527), do fazer artístico como ato cognitivo. De outro lado, a partir do segundo Pós-Guerra, o abstracionismo informal, por vezes sinonimizado ao abstracionismo lírico lato sensu, vincularam-se à ideia da manifestação ou até materialização dos sentimentos e da autoexpressão do artista.

Para além de certa desconfiança de tal dicotomização, ainda há a necessidade de esclarecermos brevemente a questão de um pretenso atraso da emergência da abstração na cultura artística brasileira, embora tal conceito já venha sendo desconstruído há tempos na historiografia da arte no país. Como bem observa Almerinda Lopes (2002, p. 2-3), a década de 1990 apresenta o início de uma virada na consideração da arte brasileira, ao ensejar "novos discursos que permitem responder a uma série de questões significativas sobre o percurso e as peculiaridades de nossa história da arte, numa relação mais direta com o contexto histórico e cultural brasileiro". Desse modo, ela denuncia maniqueísmos da relação centro-periferia, bem como engessamentos de uma periodização marcada pela falaciosa noção de atraso diante de modelos teóricos e plásticos europeus e estadunidenses.

Em relação à adoção de tendências abstracionistas por artistas brasileiros nos anos 1940, e não quando da eclosão do Modernismo nas primeiras décadas do século XX, Tadeu Chiarelli tocou diretamente o âmago da questão, ao mencionar que o modernismo brasileiro foi instrumentalizado a fim de manter o vínculo com a Europa. Contudo, o autor explica que existia um engajamento nacionalista na produção artística. Essa situação poderia explicar a não adesão à arte não-figurativa pelos artistas e críticos, que entenderiam que a arte regional e brasileira são coisas diferentes deveriam materializar apenas imagens de brasilidades (CHIARELLI, 2010, p. 121). Digno de nota é, ainda, a coexistência de tendências figurativas e não figurativas a partir dessa década, como notam Emerson Dionisio Gomes de Oliveira e Anelise Weingartner Ferreira:

[...] tomamos como particularidade desse modernismo "posterior" aos anos de 1940 uma atenta manutenção de valores plásticos da "vanguarda modernista" brasileira: busca de formas universais, valorização à centralidade autoral e aos preceitos artesanais da prática pictográfica e escultórica, apego à figuração e à linguagem abstratizante, atenção à temática identitária etc. (2013, p. 104) 


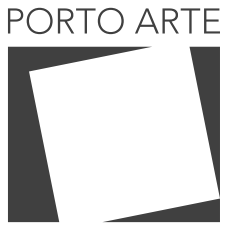

Revista de Artes Visuais

Assim, é consensual que a adoção do abstracionismo no Brasil tem início em meados da década de 1940, mas teria sido a partir da "I Bienal Internacional de São Paulo" (1951), que os artistas passaram a ganhar maior visibilidade. Foi aí também que as críticas, existentes desde os anos $1920^{2}$ intensificaram-se. É paradigmática a célebre tentativa de prevenção por Emiliano Di Cavalcanti:

O que acho porém vital é fugir do abstracionismo. A obra de arte dos abstracionistas tipo Kandinsky, Klee, Mondrian, Arp, Calders é uma espacialização estéril. Esses artistas constróem um mundozinho ampliado, perdido em cada fragmento das coisas reais: são visões monstruosas de resíduos amebianos ou atômicos, revelados pelos microscópios de cérebros doentios (DI CAVALCANTI, 1949).

Nos anos 1940, artistas que haviam se dedicado à arte social até a década anterior, como Alfredo Volpi e Aldo Bonadei, começavam desenvolver processos progressivos de abstração num registro formal. Ao lado dessas obras que se consignam ao formalismo, a abstração geométrica de matriz construtiva, é fomentada no Brasil na passagem para a década de 1950, como foi o caso da exposição dos "19 Pintores" (1947), em São Paulo, paralelamente à constituição dos principais museus no eixo então hegemônico São Paulo-Rio de Janeiro. Alguns centros latinoamericanos respondiam ativamente ao projeto expansionista do grupo europeu da Art Concret, um dos redutos do racionalismo e do funcionalismo desde os anos 1930 na Europa, com o qual alguns artistas brasileiros já haviam entrado em contato no final dos anos 1940. Os dois grupos brasileiros de Arte Concreta, o Ruptura, em São Paulo, e o Frente, no Rio de Janeiro, configuravam-se no início dos anos 1950 na conjuntura da intensa industrialização e modernização do Pós-Guerra, quando do acirramento das desigualdades sociais e contrastes seculares no país, o que suscitou críticas de cunho ideológico contra a abstração, bem como críticas relativas ao engajamento nacionalista da produção artística anterior. Neste contexto, a abstração expressiva, salvo exceções como a da franco-portuguesa Maria Helena Vieira da Silva e de Antônio Bandeira, não tinha lugar no Brasil do Pós-Guerra.

A expressão art informel foi cunhada quando da exposição "Véhémences Confrontées" (1951), pelo crítico e artista Michel Tapié, que a tornaria célebre no livro Un Art Autre, publicado no ano seguinte, no qual figuram 3 obras de Maria Martins. As expressões arte informal, informalismo ou simplesmente informal à época, tomava, assim, o sentido de uma produção artística não-formal ou aformal ou até pré-formal, passando

\footnotetext{
2- Segundo Felipe Cavalcanti, parte da crítica se divide em defesa ou ataque ao abstrato, como por exemplo, Mário de Andrade (1983-1945) "considerava o abstracionismo intelectualista, contorcionista e egoísta" (ANDRADE apud CAVALCANTI, 2018, p. 9). Compactuando com o mesmo posicionamento de Andrade, Sérgio Milliet (1898-1966) "exaltava os pintores e escultores que, embora modernos, se recusavam a qualquer compromisso com as deliciosas e decadentes brincadeiras abstratas" (MILLIET apud CAVALCANTI, 2018, p. 9). Postura diferente de Andrade e Milliet, Mário Pedrosa considerava os artistas abstratos mais conscientes, "pois haviam entendido que o aspecto documental da pintura tinha acabado" (CAVALCANTI, 2018, p. 10).
} 


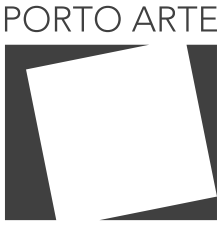

Revista de Artes Visuais

v $25 n .44$

Jul/dez 2020 e-ISSN: 2179-8001

a designar uma tendência anti-racionalista e anti-funcionalista. Pensando em termos mais extensos e guardando a consciência de profundas diferenças em relação ao Expressionismo Abstrato estadunidense, não é incomum encontrarmos aproximações dessas tendências englobadas em um sentido ainda mais abrangente de abstração expressiva, sobretudo em contraste com a abstração formalista, geométrica, que teve maior aderência no Brasil, até o final dos anos 1950.

Para compreender esta dimensão histórica do abstracionismo informal no Brasil e suas possibilidades, propomos discutir alguns aspectos da exposição "Oito décadas de abstração informal", que aconteceu no Museu de Arte Moderna de São Paulo - MASP, entre 16 de janeiro e 22 de abril de 2018, com curadoria de Felipe Chaimovich e Lauro Cavalcanti. Com o objetivo de visibilizar as produções do abstracionismo informal no país dos anos 1940 a 2010, a mostra salientou nuances de diferentes tendências, poéticas, materiais e suportes que ocorreram ao longo desses oito decênios. Nossa discussão pretende abordar as obras de Leda Catunda, Tatiana Blass e Luiz Aquila, que estão presentes nessa exposição com o propósito de contrastar certas questões em ambas as produções.

\section{Entre o abstracionismo geométrico e o abstracionismo lírico ou informal}

Durante os primeiros anos da produção de arte abstrata no Brasil, sobretudo em São Paulo e no Rio de Janeiro, os artistas mantiveram diálogos com as vanguardas europeias do segundo Pós-Guerra, o que trouxe proximidade a questões que vinham sendo debatidas em diferentes vertentes abstracionistas, desde a fundação das associações Cercle e Carré (1929), Abstraction-Création (1931), e Circle (1937), além do movimento Art Concret (1930) do período Entreguerras até a Arte Informal europeia e os Salons des Réalités Nouvelles, inaugurados em 1946. No Brasil, a discussão se intensificou a contenda entre defensores da arte figurativa e da arte abstrata, e mesmo entre diferentes vertentes abstratas ${ }^{3}$, desde argumentos formais e posicionamentos estéticos até a assunção de questões ideológicas. Cabe lembrar, nesse sentido, a intensidade e extensão de artistas e movimentos que se consagravam a temas sociais, assim como ao regionalismo, nos mais diferentes centros culturais no Brasil, o que dificultou a aceitação do abstrato. Embora essa barreira em relação à arte abstrata nunca tenha deixado de existir, mesmo que em diferentes épocas e contextos, não deixaram de surgir ou foram adotadas vertentes e movimentos abstracionistas com características peculiares.

De um lado, o Concretismo selou a vertente geométrica racionalizante em que a obra parece, por vezes, convergir com as tendências das políticas de Juscelino Kubitschek e o mote dos "cinquenta anos em cinco"4. Assim, há a afirmação da

\footnotetext{
3- Cavalcanti (2018, p. 7) explica que a alguns críticos membros do Concretismo, como Waldemar Cordeiro e Ferreira Gullar, realizavam críticas à abstração lírica/informal acentuando o problema de deixar a criação artística dependente da subjetividade do artista. Contudo, críticos como Mário Pedrosa defendiam as criações abstratas por representaram valores essenciais da obra.

4- Trata-se do projeto desenvolvimentista de Juscelino Kubitschek, nos anos 1950. Esse ideal para o campo econômico e social ficou conhecido como Programa ou Plano de Metas. Foram consolidados em um conjunto de 31 objetivos a serem alcançados em diversos setores da economia, incluindo a construção de Brasília e a transferência da Capital Federal.
} 


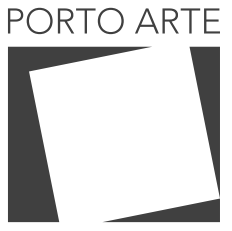

Revista de Artes Visuais

Arte Concreta como a mais adequada vanguarda para um país que estava em forte crescimento econômico, modernizando-se industrialmente. Segundo Maria de Fátima Morethy Couto, há

[...] a exposição de Max Bill no Masp em 1950 e a participação da delegação suíça na primeira Bienal de São Paulo. 0 prêmio de melhor escultor outorgado a Max Bill nessa ocasião parece confirmar o impacto de sua obra sobre artistas e críticos brasileiros. Entretanto, a prodigiosa vitalidade encontrada pela arte geométrica e suas variantes em diversos países da América do Sul no pós-guerra levou diversos intelectuais a buscar as raízes desse fenômeno no contexto político-econômico do continente sul-americano (2000, p. 203).

Diante essa tarefa, a arte assumiria uma dimensão colaborativa e coletiva. O Neoconcretismo, que derivou em parte do debate sobre as abstrações nos 1950, sobretudo do Concretismo, pautava a autonomia da obra de arte em relação aos suportes da tela e da escultura, opondo-se às bases ditas tradicionais da arte, entendidas tanto como a tradição plástica ocidental, como o Modernismo. A respeito da tensão entre os Grupos Ruptura e Frente, bem como o Neoconcretismo, persistente na historiografia da arte brasileira, Luiz Aquila entende que

Talvez os concretos, em São Paulo, tenham criado essa linguagem completamente universal, onde o indivíduo não conta, onde não existe a trama, a intriga, onde a psicologia do indivíduo não entra. Isto foi negado depois no Rio quando os neoconcretos começaram a fazer uma coisa muito mais sensível, e depois no período da arte conceitual - como se tivesse uma arte que fosse só conceito e outra que fosse só expressão individual ou que fosse só uma narrativa romântica do indivíduo. Acho que é uma dicotomia falsa criada pelos críticos. (AQUILA, 2008, p. 10)

A abstração expressiva continua em expansão na Europa com Arte Informal e nos Estados Unidos com o Expressionismo Abstrato, até, pelo menos, meados dos anos 1960. Malgrado a diferença entre essa vertente na Europa e Estados Unidos, ela engloba as poéticas do gesto, do signo e da matéria (ARGAN, 1993, p. 527ss), além de dialogar francamente com a abstração onírica e com a abstração lírica. Cabe especificar uma diferença entre a noção de abstração lírica no Brasil e na Europa ${ }^{5}$, onde é identificada

\footnotetext{
5- A expressão abstração lírica foi cunhada pelo crítico Jean José Marchand e pelo pintor George Mathieu quando da exposição "L'Imateriel" em Paris (1947). Ela derivava da abstração expressiva, mesclando poéticas sígnicas e gestuais, mas com um peso semântico que remonta à subjetividade da criação desde os primeiros poetas líricos da Grécia, que expressavam seus sentimentos pessoais envolvendo também uma ascendência e/ou inspiração surrealista nos processos de criação individualizados, reportando ao automatismo da expressão pura do artista, censurando a intervenção da consciência.
} 


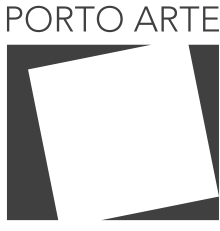

Revista de Artes Visuais

v. 25 n. 44

$\mathrm{Jul} / \mathrm{dez} 2020$ e-ISSN: 2179-8001

à chamada nova Escola de Paris, no Pós-Guerra, com artistas franceses e estrangeiros residentes em Paris, tendo sua principal vertente na França conhecido como Tachismo.

Residia justamente aí a crítica de Ferreira Gullar (2015, p. 120), que caracterizou o abstracionismo informal por meio do desprezo do rigor geométrico e pela arte figurativa. Porém, identificou essa tendência como conservadora, pois apesar da exigência por uma arte autônoma, essa tendência não conseguiria superar os limites da pintura e da escultura, conforme, aliás, seria o caso do Concretismo e depois do Neoconcretismo, aos quais o próprio Gullar se vinculou como crítico e como poeta, além de ter elaborado seu Manifesto. Os apontamentos de Gullar são compreendidos ao observar-se o desenvolvimento do abstracionismo geométrico, sobretudo nas expressões do Concretismo, nas concepções de Waldemar Cordeiro e Décio Pignatari6. Segundo ambos os integrantes do Concretismo em sua expressão paulista, esse movimento tinha a intenção de reconstituir a forma de conhecimento sensível nos seus níveis mais elementares, "antes de qualquer formulação conceitual, discursiva, nesta zona em que o objeto é dado à pura intuição" (NUNES, 2004, p. 60). Daí a expressão da crítica concretista à arte informal, identificada como lírica, num sentido depreciativo, como evidenciam Fernando Cocchiarale e Anna Bella Geiger:

\begin{abstract}
A ideia era de uma arte que estivesse ao nível da evidência em que você formasse ideogramas complementares e simples da visualidade que poderiam ser encontrados numa porta de tinturaria, ou que um operário desenhasse e que uma criança fizesse. Trata-se de fazer uma arte um pouco anórmica que encontrasse os fundamentos de sua própria articulação. Não era uma arte para pintar quadros, eram matrizes para futuras artes. (COCCHIARALLE; GEIGER, 1987, p. 72)
\end{abstract}

Para a abstração informal, as questões econômicas e sociais poderiam ser assimiladas à subjetividade do artista e a própria interpretação das obras pelo espectador. Esse posicionamento distinguia-se, sobretudo da proposta do Concretismo. Porém, Chaimovich (2018, p. 16) entre outros, identifica laços da abstração informal com a proposta da exposição "Nova Objetividade Brasileira" (1967), ocorrida no museu de arte moderna do Rio de Janeiro que, para Cordeiro o grupo

estabelecia seus antecedentes nas movimentações concreta e neoconcreta e configurava uma tradição viva da arte brasileira de vanguarda. Através das colocações de Cordeiro, percebia-se a trajetória entre aqueles antecedentes e os da Nova Objetividade (REIS, 2006, p. 46). 


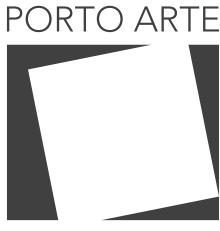

Revista de Artes Visuais

$\vee 25 n .44$

$\mathrm{Jul} / \mathrm{dez} 2020$ e-ISSN: 2179-8001

Artistas que fizeram parte dessa exposição, "envolvidos na negação de formas tradicionais de obra de arte" (CHAIMOVICH, 2018, p.17), buscavam pensar novas maneiras de chegar ao espectador para uma recepção da obra que tivesse consequências sociais e econômicas. Com a ruptura proposta pelo Neoconcretismo, sobretudo pelo Nova Objetividade, Chaimovich (2018, p.17) indica uma mudança de paradigmas, segundo a qual os artistas rompem com a ideia da tela e do cavalete. Esse acontecimento favorece os abstracionistas informais que ousam ultrapassar os limites da moldura, ainda que diferentemente dos concretistas.

Esses diálogos entre os abstracionistas expressam-se, de modo geral, na produção de suas obras, como se percebe na exposição "Oito décadas de abstração informal", constituída a partir das obras abstratas do acervo do Museu de Arte Moderna de São Paulo e da Coleção Roberto Marinho.

A partir dos anos 1970 no Brasil, o abstracionismo informal passa por profundas modificações, conforme comenta Chaimovich (2018, p. 19), ao dizer que essas obras passaram a ser cada vez mais experimentais e menos intimistas. Assim, Maria Bonomi, por exemplo, apresentava suas xilogravuras de grandes dimensões, afastando-se da pequena escala, em que o artista executava sua obra sozinho, para revelar um método coletivo de trabalho. A imagem do artista abstrato que realiza um trabalho solitário se modifica e cede aos grupos. As obras de Luiz Aquila expandem-se para outros suportes fora da tela. Aquila não deixa de ter liberdade técnica ou de expressar sentimentos na realização de suas obras, entendendo que ao flexibilizar o suporte fortalece o experimentalismo com outros materiais na abstração informal. Contrariando os comentários de Ferreira Gullar, a abstração informal no Brasil remodelou-se e, se não ultrapassou, procurou problematizar o caráter então entendido como tradicional da pintura e da escultura. A partir dos anos 1970 e 1980, artistas como Leda Catunda, Karin Lambrecht e Fernando Lindote são elencados por Chaimovich (2018, p. 22) como representantes dessa significativa abertura.

Nos anos 1980, o material plástico aparece com mais vivacidade nas obras e as cores acompanham o mesmo movimento. 0 conjunto de artistas que se celebrizou sob o epíteto de Geração $80^{7}$ buscava um retorno à pintura e escultura, diante de diversos críticos à continuidade da pintura como categoria artística viável na arte contemporânea, ao longo das décadas de 1960 e 1970. Salienta-se que o contexto histórico da existência dos grupos anteriores - Ruptura, Objeto 65, Objeto 66, Nova Objetividade - é diferente da Geração 80, que colhia os novos ares pós-ditadura civil-militar brasileira, não podendo negar seu sucesso, tal como o da exposição "Como vai você, Geração 80?" (1984), ${ }^{8}$ recrudescendo as galerias e o colecionismo e, portanto, dinamizando o mercado da arte conforme nos explica Fabiana Della Coletta Monteiro (2017, p. 43).

O experimentalismo na abstração informal, lírico ou não, levou os artistas dos anos 1980 a utilizarem outros materiais. Outros/as artistas também ultrapassam es-

\footnotetext{
7- Segundo Luiz Aquila, a dita Geração 80 foi um grupo de estudantes que se uniram para pensar a arte de seu tempo. A proposta foi de Rubem Breitman e contou com vertentes artísticas, mas prevalecendo a pintura tanto com artistas do Rio de Janeiro quanto de São Paulo (AQUILA, 2008, p. 15), mas não sem críticas com diferentes motivações. 


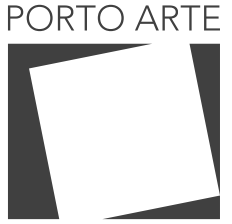

Revista de Artes Visuais

V. $25 n .44$ Jul/dez 2020 e-ISSN: 2179-8001
(Fig. 01): Leda Catunda. Couros 1993. Acrílica sobre couro e tela. $170 \times 252 \times 8 \mathrm{~cm}$. Coleção MAM doação da artista.

Créditos da imagem: Oito décadas de abstração informal: 1940 -2010. Ministério da Cultura, Instituto Casa Roberto Marinho e Museu de Arte Moderna de São Paulo, 2018 ses limites marcados pela tradição da pintura de cavalete, como evidencia Leda Catunda, "que pinta uma obra sobre tiras de couro que são utilizadas no lugar das pinceladas, sobretudo faixas de elemento tridimensional como se fossem camadas pictóricas" (CHAIMOVICH, 2018, p.21). Na obra Couros (1993), ela utiliza das linhas curvas, diagonais e horizontais, formadas por tiras. As cores oscilam entre tons terrosos, possibilitando à artista atingir uma harmonização. 0 contraste ocorre por meio da simetria em que as tiras de couro são inseridas na obra.

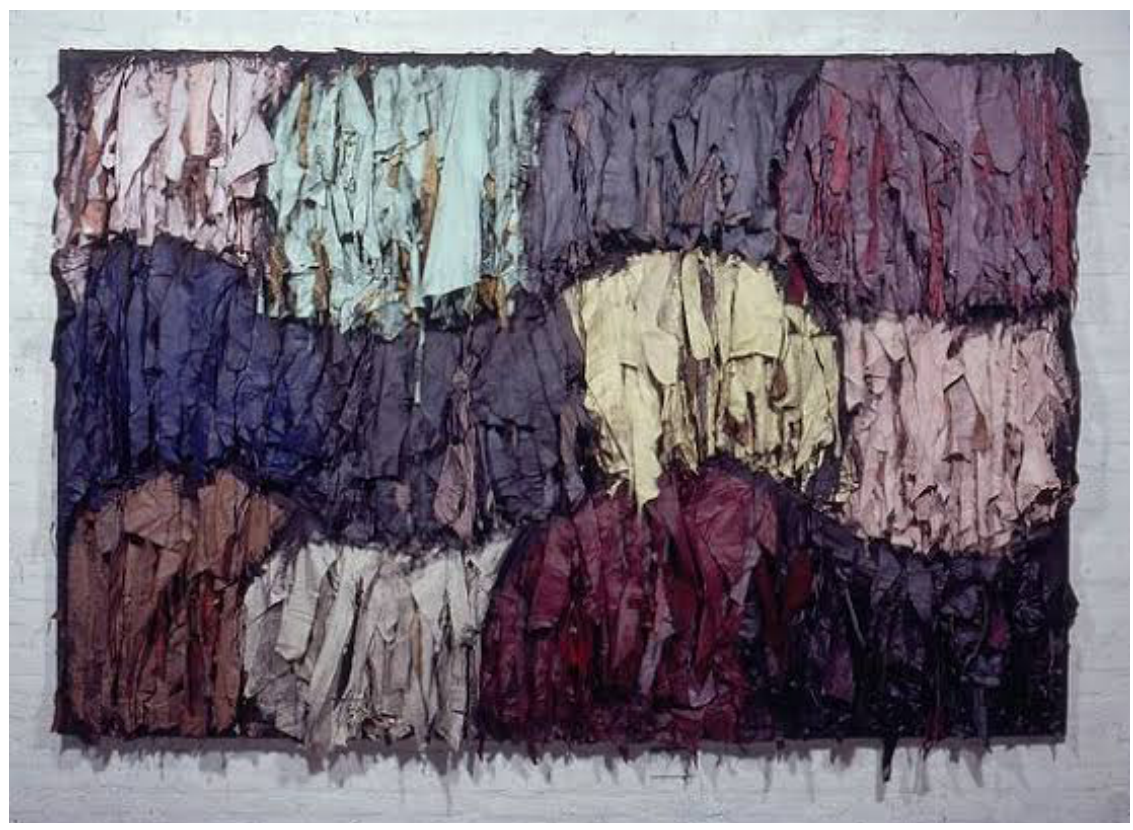

Nos anos 1990, os instrumentos tradicionais reafirmam-se como estratégia para enfatizar os materiais gráficos, pictóricos e escultóricos, por meio de obras gestuais de Antônio Helio Cabral, Carlos Uchôa e Maria Tereza Louro.

\section{Abstracionismo informal: entre o moderno e a contemporaneidade}

Hubert Damisch, no seminário intitulado "Observações sobre a abstração" (2006) afirmou que a contemporaneidade alijou os estudos sobre o abstrato e a própria arte abstracionista restringindo ambas as produções, artística e teórica à Modernidade ${ }^{10}$. Desse modo, a abstração teria sido reduzida a algo do passado. 0 contexto desse diag- 


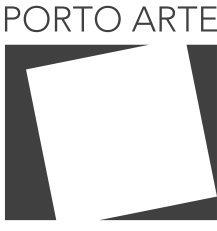

Revista de Artes Visuais

v $25 n .44$

Jul/dez 2020 e-ISSN: 2179-8001

nóstico era o da tratativa do convite dirigido a Damisch para realizar a curadoria da grande exposição de reabertura do Centro Georges Pompidou em Paris, em 2000. Após a troca da direção do museu, a exposição cujo título por ele proposto seria "A disputa pela abstração"11 foi cancelada, segundo Damisch (2009, p. 133) devido à sua intenção de problematizar o entendimento da contemporaneidade sobre que é o abstrato.

Em seu diálogo com Yve-Alain Bois, Denis Hollier e Rosalind Krauss (1998, p. 13), Damisch salienta a necessidade de aprofundamento dos estudos sobre o que é o abstrato. Para ele, a arte abstrata não se reduz à pintura e escultura, sendo essas artes mais uma maneira de mostrar fenomenologicamente um conteúdo amorfo. Isso fica evidente no momento em que ele utiliza como exemplo o caso da música e das cores. A música possui um caráter abstrato anterior ao de qualquer outra arte devido às suas sonoridades. Vincent Van Gogh e Paul Gauguin, segundo Damisch (1998, p. 14), desenvolveram as sonoridades de cor. Kandinsky possibilitou uma aproximação da pintura com a música a partir do conceito de ressonância no livro Do espiritual na arte e na pintura em particular (1912).

Conforme foi esmiuçado por Vera Pugliese (2018, p. 3858), Damisch explicou que mesmo a compreensão de arte abstrata sendo transformada em um objeto do século $\mathrm{XX}$, as investigações sobre esse paradigma continuam sendo realizadas na contemporaneidade. Aborda-se o abstrato como um conteúdo exclusivamente pertencente às vanguardas modernas. Damisch, porém, propõe aos historiadores da arte entender a situação: "de um presente sempre passado, irrevogavelmente passado e sempre por vir, irremediavelmente por vir" (DAMISCH, 2009, p. 134 tradução livre).

No mencionado diálogo de 1998, Damisch indicava a necessidade de distinguir o abstracionismo do processo abstrato. Ao realizar essa distinção, é possível perceber que a abstração, considerada como modo operativo ou como processo do pensamento, supera todos os limites do que é abstrair no projeto de arte da modernidade. "Rompendo com a noção temporal e com as barreiras conceituais, relegando o status de "gênero" (DAMISCH, 2009, p. 136, tradução livre). Esse alargamento do conceito de arte abstrata possibilita que o conceito e as operações abstratas sejam separados de um programa moderno, favorecendo o entendimento dos motivos pelos quais o abstrato ainda aparece na contemporaneidade.

Quatorze anos após o seminário de Damisch, malgrado a resistência à problematização da noção de abstrato e interrogar seu processo de historicização, reconhecemos algumas iniciativas de portes, intenções e repercussões variadas, que talvez evidenciem a urgência de reverter o quadro indicado por ele, como foi o caso da mostra "Inventing Abstraction: How a radical idea changed the modern art, em 2012, no Museum of Modern Art" - MoMa de Nova York.

Com o avanço crescente de novas tecnologias, a quantidade exorbitante de imagens, da propaganda e da banalização das imagens figuradas, a arte abstrata informal pode alcançar um debate político de negação ao consumo visual e como estratégia de resistência.

11- Damisch (2009, p. 133) indica que o título Remarks on Abstraction deveria ser recebido como uma nota em uma folha de prova de uma gravura. 


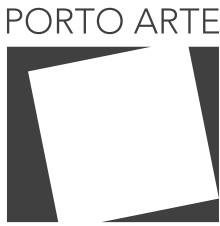

Revista de Artes Visuais

1.25 n. 44 $\mathrm{Jul} / \mathrm{dez} 2020$ e-ISSN: 2179-8001
Figura 02: Tatiana Blass Poltrona. 2003. Óleo sobre tela. $70 \times 90 \mathrm{~cm}$. Coleção MAM doação do artista.

Crédito: Oito décadas de abstração informal: 1940 -2010. Ministério da Cultura Instituto Casa Roberto Marinho e Museu de Arte Moderna de São Paulo, 2018
Desde os anos 1980, com o objetivo de negar os regimes de visualidades propostos pelo cotidiano contemporâneo, surgem obras que carregam o título que aludem ao figurativo, como a obra Poltrona de Tatiana Blass (1978). 0 jogo com a linguagem possibilita à artista e ao espectador questionar os limites do visível.

A obra de Tatiana Blass não apresenta a totalidade do objeto nomeado em seu título. A imagem é um recorte do objeto em toda a sua abundância. As formas sugerem uma certa complementariedade por meio da justaposição sugerido a partir do contraste de cores vivas. A obra provoca no espectador uma inconveniente busca pelo referente.

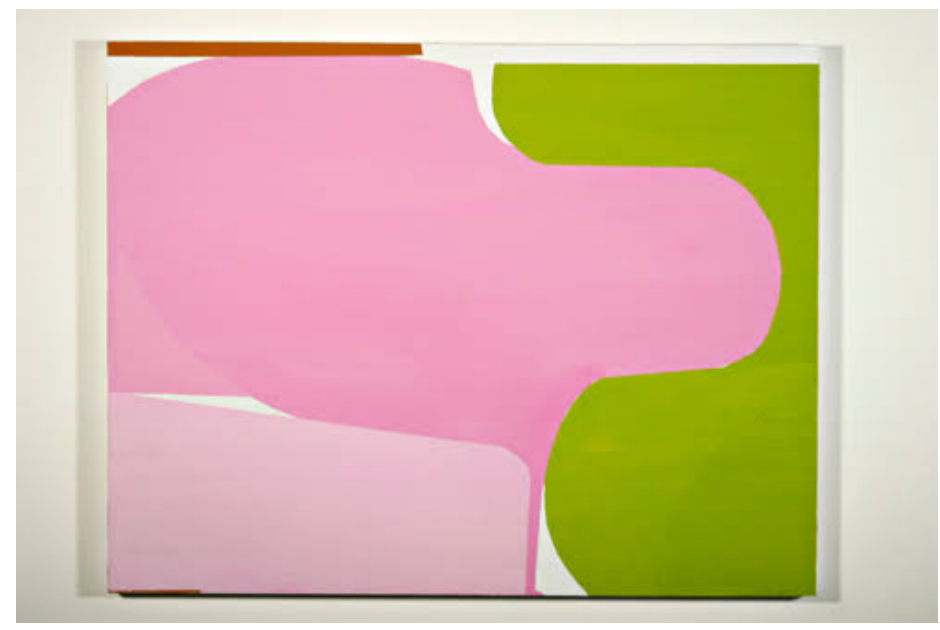

Blass realiza pinturas, vídeos, esculturas e instalações. Sua carreira teve início em meados de 1998, quando ingressou na cena artística paulista, participando de exposições coletivas e individuais no Brasil e no Exterior. A artista integrou a $29^{a}$ Bienal Internacional de São Paulo (2010) e também foi finalista do prêmio Nam June Paik Award, na Alemanha em 2008. Durante o período de 2002 e 2007, ela realizou uma série de pinturas, em que apresentava um percurso para pinturas abstratas. Mas diferente de pesquisas formais, como as que celebrizaram a obra de Josef Albers nos anos 1960, na série dos Square, Blass parece a um só tempo reunir preocupações sensoriais e conceptuais, sem abrir mão do informal:

Foram feitas pinturas com tinta a óleo sem diluição, com cores intensas e luminosas, "artificiais", quase enjoativas. Elaboradas com máscaras recortadas em papel e fita-crepe que delimitavam as áreas de tinta, vinham de um procedimento próprio da colagem, no sentido de igualar forma e cor. A vontade estava em estabelecer uma convivência, em que mesmo a estranheza não trouxesse discordância, obtida por uma passagem não brusca entre elementos diferentes. Esta passagem ocorre por campos de cor com aproximações tonais 


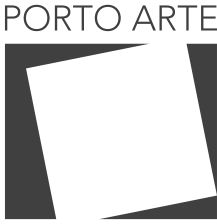

Revista de Artes Visuais

v. 25 n. 44 $\mathrm{Jul} / \mathrm{dez} 2020$ e-ISSN: 2179-8001
Figura 03: Tatiana Blass Paisagem em listras, 2004. Óleo sobre tela - $70 \times 100 \mathrm{~cm}$ Crédito: Tatiana Blass / Tatiana Blass. - 1. ed. - Rio de Janeiro Automatica, 2016 e com uma vibração semelhante de luz, e pela articulação através das formas com limites curvos, que criam contatos macios entre elas (BLASS, 2016, p. 161).

Ela não se restringe ao âmbito do abstracionismo informal, mas busca, por meio de outras categorias artísticas, questionar as dimensões da imagem midiática na sociedade. Assim, obras como a videoinstalação Electrical Room (2013) que ocupou dois espaços do Museum of Contemporary Art em Denver, em que a artista questionou a difusão tecnológica de um mundo globalizado. A obra consiste em imagens de homens e mulheres projetadas separadamente em televisões. Existe uma barreira em relação à linguagem entre as pessoas, que necessitam de um tradutor para conseguirem comunicar-se. Em determinado momento é disparado uma fumaça que encobre os televisores, tornando opaca a imagem dos participantes. Assim, acontece um desentendimento em relação à linguagem e as pessoas passam a ignorar o diálogo. Esse não-lugar da conversa demonstra a dificuldade com a linguagem.

Na obra Paisagem em listras (2004), a artista trabalha com a opacidade e transparência. A cor vermelha ocupa boa parte da tela, posicionada na horizontal, enquanto que as outras cores permanecem ao fundo. Há novamente a sugestão de um referente que não pode ser determinado na obra, apenas sugerido horizontalização do suporte a aproximação do gênero da paisagem.

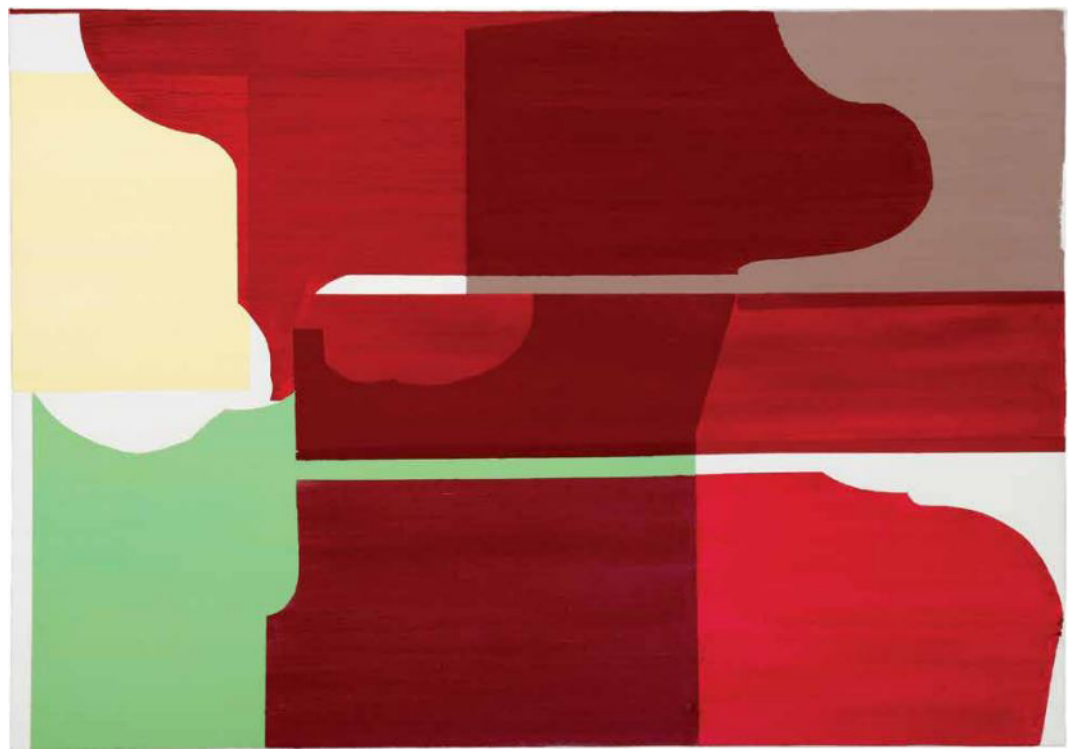

Escoubas (2005, p. 170) explica que para Henri Maldiney o objetivo da arte não é imitar e sim aparecer. E ao considerar a ambiguidade do termo imagem, ele divide a "visão estética" da "visão imagificante". 0 primeiro termo é definido como a afetação 


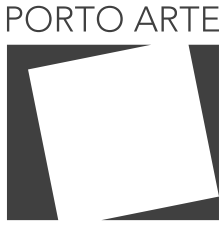

Revista de Artes Visuais

$\vee 25 n .44$

$\mathrm{Jul} / \mathrm{dez} 2020$ e-ISSN: 2179-8001

pelo ritmo das formas ou da luz, e "mede aquilo a que, de direito, temos de chamar abstração criadora do pintor" (MALDINEY apud ESCOUBAS, 2005, p. 170). 0 segundo termo aplica-se à visão imaginativa que se tem do objeto. Maldiney indica que é preciso separar a visão estética da "visão imagificante", pois a imagem imagificante proporciona um olhar intencional que reconhece e nomeia um objeto. Enquanto que a "visão estética" não é intencional e possibilita uma maneira de se olhar para si e para o mundo.

Assim, de acordo com Escoubas, o espaço do quadro exige um exercício do olhar, pois "põe em obra um sentido do ser como aparecer", realizando um retorno ao sentido originário do termo phainesthai. Neste sentido, as palavras de Adauto Novaes em O Olhar (1988, p. 10) elucida, ao dizer que "[...] o olhar deseja sempre mais do que o que lhe é dado a ver." ao passo que existe uma procura pelo significado da obra, pela instância em que a arte passa a fazer sentido na vida, seja social ou individual de cada humano.

Nas obras de Tatiana Blass, a artista parece utilizar-se de processos abstratos para negar essa produção exorbitante de imagens que foram capturadas pelo consumo. A cor aparece como uma questão para a artista, que nas palavras de Luiz Camillo Osorio

[em suas obras] A intuição aí não funciona como algo espontâneo, fácil, que daria à sua poética um caráter um tanto ingênuo. Não. 0 que se apresenta é uma sabedoria quase física dos materiais, principalmente das cores, que funcionam por contrastes de textura e temperatura. Uma pintura muitas vezes feita com materiais comuns e que apela ao nosso sentido tátil. Cores exaltadas e tímidas convivem sem se acomodarem (2005, s./p.).

Além dessa dimensão que vem sendo proposta a arte abstrata, os curadores da mostra brasileira "Oito décadas de abstração informal" apontam para as dificuldades encontradas pelos artistas ao evidenciarem a necessidade de uma arte expressiva, e é possível ver o horizonte entreaberto pela arte contemporânea, período em que não há sentido em desacreditar obras que recorram à subjetividade. Há uma flexibilização nas regras de composição e o meio artístico permite entrecruzamentos de diferentes suportes e técnicas. Essa liberdade do contexto contemporâneo permite que artistas se alinhem ao abstracionismo informal sob uma perspectiva moderna para responder questões contemporâneas.

$\mathrm{Na}$ arte contemporânea, uma produção jamais será desqualificada como simples interjeição pessoal à qual faltaria a inserção num discurso estruturado maior. No território das artes, com as fronteiras já transpostas e esgarçadas, as especificidades são mais valorizadas que o pertencimento a projetos modelares mais amplos. Nem sempre foi assim. Talvez agora seja um bom momento para revermos produções abstratas anteriormente descartadas como subjetivas e hedonistas, às quais faltariam um tom local ou inserção num plano coletivo norteador do futuro (CAVALCANTI, 2010, p. 9). 


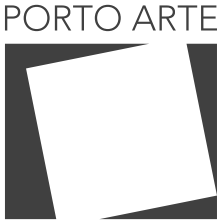

Revista de Artes Visuais

v. 25 n.44 Jul/dez 2020 e-ISSN: 2179-8001
Figura 04: Luiz Aquila. Gradil 1979. Óleo sobre tela. 146,3 x $113 \mathrm{~cm}$. Crédito: Oito décadas de abstração informal: 1940 -2010. Ministério da Cultura Instituto Casa Roberto Marinho e Museu de Arte Moderna de São Paulo, 2018.
Mas a obra de Luiz Aquila parece se distanciar de Blass, inserindo-se em um rol de artistas que atravessam décadas e continuam com o projeto moderno da arte abstrata informal. Assim, entendemos que ele é um dos artistas que defendem deliberadamente a utilização de soluções modernas para questões contemporâneas, como uma tomada de posição. Desde os anos 1960, Aquila está na cena do abstracionismo informal. Carioca, nascido em meados dos anos 1940, esteve sempre mergulhado no fazer artístico, tendo sido aluno de Oswaldo Goeldi, Aluísio Carvão e Tiziana Bonazzola. No Rio de Janeiro, ao lecionar no Parque Lage, onde presenciou o nascimento da exposição "Como vai você, geração 80", em 1984 e do grupo de artistas, em sua maioria do eixo Rio/São Paulo, que questionaram a arte conceitual, o Concretismo e o Neoconcretismo, retomando a utilização da pintura e da escultura como expressões da arte. Nos anos seguintes, torna-se diretor da Escola de Artes Visuais do Parque Lage (1988 - 1990). Aquila realizou mais de duzentas exposições (individuais e coletivas), participou das Bienais de São Paulo de 1983, 1985 e 1989 e da Bienal de Veneza em 1978. Além de participar da exposição "Oito décadas de abstração informal", o artista recentemente tem sua individual "Luiz Aquila III Milênio - criação em aberto", representando com seu trabalho a arte abstrata informal contemporânea, no Museu Nacional de Belas Artes/ Ibram no período de 31 de agosto a 1 de dezembro de 2019.

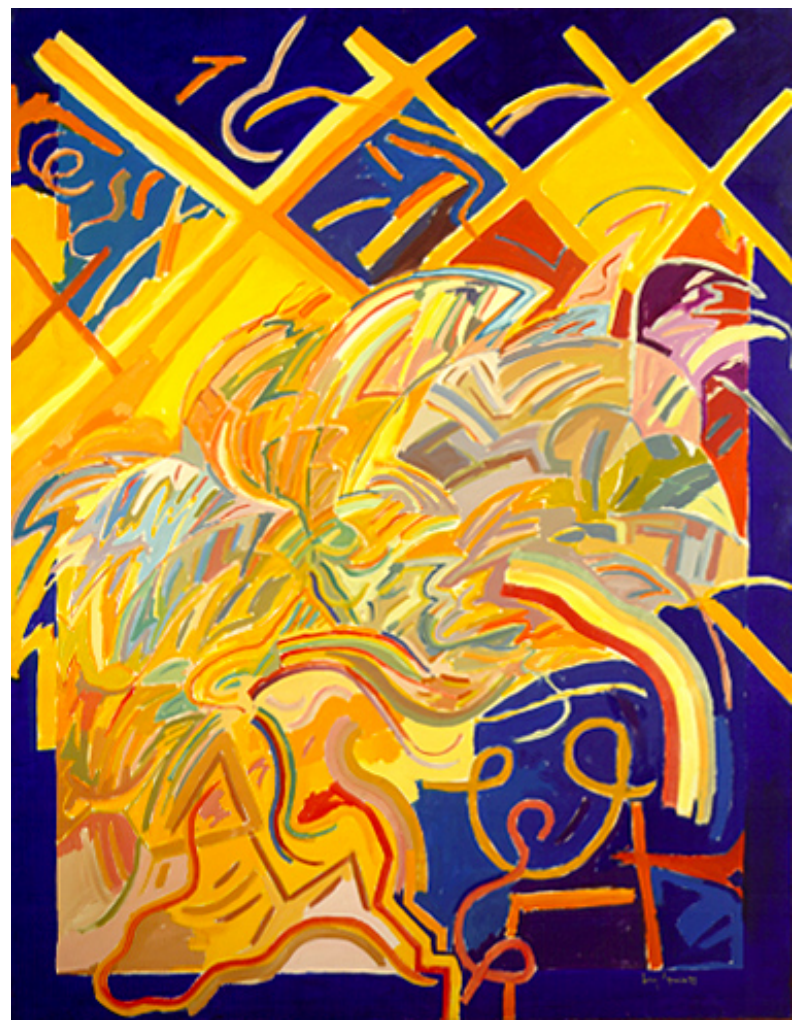




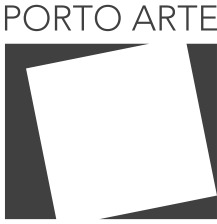

Revista de Artes Visuais

1.25 n. 44 $\mathrm{Jul} / \mathrm{dez} 2020$ e-ISSN: 2179-8001
Figura 05: Luiz Aquila. Urgência I, 1985. Acrílica sobre tela. $240.00 \mathrm{~cm} \times 260.00 \mathrm{~cm}$. Crédito: URGÊNCIA I. In: ENCICLOPÉDIA Itaú Cultural de Arte e Cultura Brasileiras. São Paulo: Itaú Cultural, 2019
No início de sua carreira, ele adotava uma postura intimista que variava entre o abstracionismo informal e o geométrico. Ele utilizou predominantemente cores primárias em sua obra Gradil (1979). Ao fundo, o azul demonstra a distância e a frieza do objeto nomeado na obra. À frente, o amarelo sobrepõe-se trazendo calor à paleta. No centro da tela, o amarelo é posto paralelamente ao azul, intensificando o contraste. Observa-se a utilização de linhas horizontais e diagonais, que por vezes contrapõem-se, formando um aglomerado no centro da composição. No canto esquerdo da obra percebe-se uma das poucas linhas horizontais, quase que isolada das demais. Para Chaimovich (2018, p. 19), a obra possui "padrões quase regulares no plano de fundo, contrastados com linhas orgânicas no primeiro plano".

Em Urgência I (1985) existe uma predominância da cor sobre as linhas. O vermelho projeta-se à frente, quente, saturando o centro do quadro. No meio, as linhas mostram-se diagonais, expelindo para as margens as linhas curvas. A obra parece dicotômica em relação ao uso da cor: o quente ocupa a parte superior da tela, enquanto que a parte fria composta por linhas curvas permanece ao fundo. As obras de Aquila aparentam convocar essa tensão entre os elementos dispares.

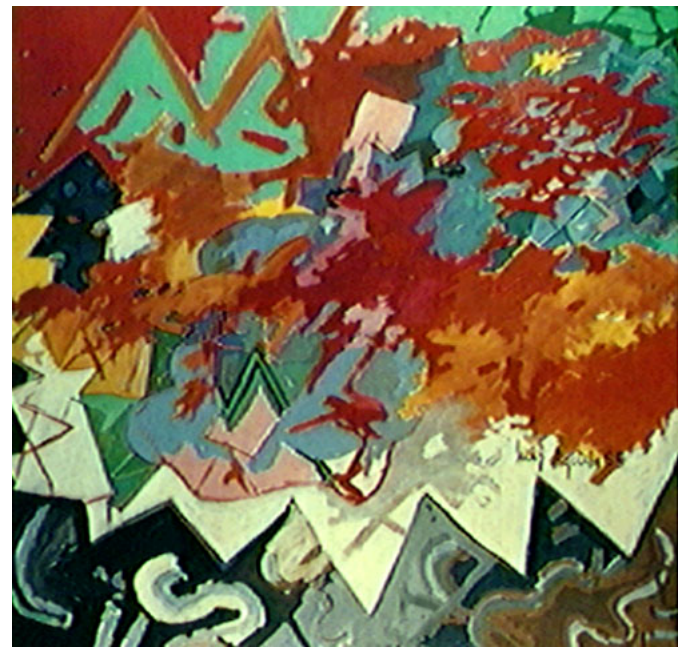

Para o artista, a pintura tem uma dimensão de organizar e transparecer os sentimentos, de trazer ao visível o que ultrapassa os limites da materialidade. A utilização da cor também é entendida como relacionada às emoções.

Então, a grande importância da arte, do nicho arte, do nicho cultural arte é essa: um espaço onde as pessoas podem organizar sua emoção, onde o espectador, o outro, se identifica e se organiza também através da obra ou do processo criado por um artista (AQUILA, 2008, p.10). 


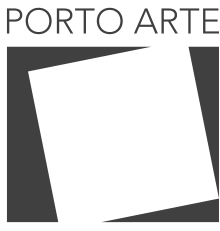

Revista de Artes Visuais

Aquila entende que no Brasil existe uma vontade em esconder suas raízes, em negar a cor e a expressividade dos sentimentos. Então a sua proposta é trabalhar com linhas, que expressam a razão em contraste com as cores. Esses aspectos demonstram resquícios românticos nas composições de sua obra:

Na verdade há uma dificuldade com a cor na arte brasileira. E há uma vontade de bom gosto no Brasil. Há um preconceito de gosto no Brasil. Há a vontade de se ter uma arte de bom gosto no Brasil, por isso a arte geométrica é tão bem aceita nas famílias, no seio das famílias brasileiras, porque ela é comportada. Ela é equilibrada, ela não tem transbordamento (AQUILA, 2008, p. 16).

No olhar de Frederico Morais (1993, p. 24), Aquila analisa as condições para a pintura e estabelece uma relação com ela, com a finalidade de manter seu processo de criação em aberto, sujeito a alterações, fluente, sempre em andamento, assim como nossa subjetividade. Esse entendimento da arte ser fluente e modificar-se ao passo que a subjetividade humana também está em movimento, faz com que a arte abstrata informal permaneça em debate.

Para analisar a preocupação de Aquila tomamos como exemplo uma figura da literatura kunderiana chamada de artista Jaromil. Milan Kundera em A vida está em outro lugar (1973) por meio do personagem do poeta Jaromil, evidencia os efeitos dos estados totalitários que controlam as artes e todas as formas de expressão. Nesse contexto de opressão e controle, o poeta decide produzir poesia para o partido vigente, empobrecendo significativamente o seu fazer artístico, pois vivendo em uma ode ao regime político e aos artistas semelhantes, era avesso ao diálogo com o outro, negando toda forma de diversidade.

Essa proposta de arte seguida pelo personagem Jaromil está distante da busca pelo Sublime. Na Crítica da faculdade do juízo (AA, 05: 25) Immanuel Kant define a tentativa de mostrar o ilimitado, o que não consegue ser conceituado pelos formatos sensíveis, como um modo de tornar visível o Sublime. Esse pode ser encontrado em representações amorfas que se assemelham à razão. Em seu paradigma, o Sublime acolhe o sentimento de dor e ao mesmo tempo de prazer, leva à contemplação do espectador, à reflexão diante a obra.

Essa incompreensão do objeto que é arrebatadora para o espectador é comentada por Jean-François Lyotard:

O sublime é outro sentimento. Ocorre quando, pelo contrário, a imaginação falha ao "presentificar" um objeto que veja, nem que seja apenas em princípio, entrar em concordância com um conceito. Temos a Ideia do mundo (a totalidade daquilo que é), mas não temos a capacidade de dar um exemplo dele (1993, p. 21). 


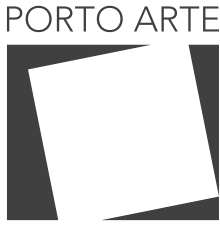

Revista de Artes Visuais

$\vee 25 n .44$

$\mathrm{Jul} / \mathrm{dez} 2020$ e-ISSN: 2179-8001

Com as obras de Blass e Aquila é possível observar uma tentativa de presentificar ao público o Sublime, ainda que seja por percursos diferentes. Blass aborda a quebra da expectativa em relação ao objeto. Quando a legenda indica um objeto reconhecível, de uso cotidiano, a obra apresenta uma imagem não vinculada ao título. A linguagem expande a compreensão do formato poltrona e convida o espectador ao estranhamento, à busca por definição. Em contraponto ao desconforto, as cores suavizam a obra e a tornam agradável. Essa busca pelo paradoxo aproxima-se do Sublime. Nas obras de Aquila a oposição entre as linhas e cores realça o contrate do quente com o frio, o desconforto e com a harmonia - consequências da interioridade do artista - instigando no espectador buscar o Sublime.

Portanto, um artista semelhante ao personagem Jaromil, não possui a preocupação com o aspecto reflexivo da obra, prescindindo da necessidade de espanto diante da obra. A proposta da busca pelo Sublime reforça o compromisso com uma arte, seja ela nos paradigmas modernos ou contemporâneos.

Às críticas às práticas sociais contemporâneas, Aquila propõe uma retomada do abstracionismo informal, mesmo que seja sob paradigmas modernos. Diferentemente dele, Blass além de utilizar processos abstratos, busca ressignificar a própria ideia de figuração através de instalações ou pinturas em um sentido ampliado.

\section{Considerações finais}

Ao observar o atual debate historiográfico artístico sobre a abstração no Ocidente e em especial no Brasil, constata-se uma tensão interpretativa que permite questionar o entendimento dos processos abstratos contemporâneos à luz das vanguardas abstracionistas. Para tanto, foi preciso seguir as investigações de Hubert Damisch, que propõe uma distinção metodológica do abstrato e do abstracionismo. Como vimos, a existência do abstracionismo - como vanguarda moderna - intensificou a problemática envolta do paradigma da figuração e propôs a arte abstrata como uma arte pura. Essa concepção de arte permitiria ao artista dimensionar ao plano fenomênico as tensões resultantes do conceito do Sublime kantiano.

Consequentemente, entendemos que a arte abstrata não só sobreviveu às tentativas coloniais de torná-la exclusividade do Ocidente, tornando-se perigosa durante o período da censura nazista, sob a expressão arte degenerada. Para um estado da arte a partir dos anos 1950 na Europa e especificamente no Brasil, a declarada morte da pintura consistiu em uma ruptura com os suportes tradicionais da mesma. Com seu caráter intimista desviou-se da censura do AI-5 e da ditadura civil-militar brasileira.

O incômodo pulsante causado pelo abstrato sobreviveu através do tempo e transita entre as artes e as diferentes linguagens artísticas, evidenciando a necessidade das análises historiográficas da arte. Sob a luz dos trabalhos de Leda Catunda, Luiz Aquila e Tatiana Blass, é possível perceber que é inegável a presença do abstrato na contemporaneidade, ainda que se apresente de dois modos: por meio do paradigma moderno abstracionista ou presentificando-se por meio de outras linguagens como a videoarte e a pintura em um campo ampliado. A inscrição do 


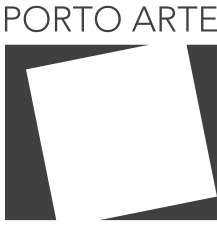

Revista de Artes Visuais

v $25 n \cdot 44$

$\mathrm{Jul} / \mathrm{dez} 2020$ e-ISSN: 2179-8001

abstrato nas linguagens artísticas contemporâneas apresenta-se como um convite ao espectador para experimentar novas maneiras de olhar os objetos, expandindo seu repertório artístico.

Exposições como a "Oito décadas de abstração informal", ao buscar aglutinar os artistas em uma determinada orientação de acordo com a cronologia, na mesma medida em que colocam em pauta a necessidade de repensar o lugar da arte abstracionista tanto na historiografia da arte quanto na arte contemporânea, correm o risco de conduzir a compreensão da arte abstrata - no sentido damischiano - e não tocam na problemática do abstrato. Entendemos que a arte abstrata expressiva ou informal assumiu significações diferentes desde os anos 1950 e que a suas flexibilizações e mutações na contemporaneidade indicam que a investigação sobre a temática ainda é pertinente.

\section{Referências}

BLASS, Tatiana. Tatiana Blass. Rio de Janeiro: Automatica, 2016.

BOIS, Yve-Alain; HOLLIER, Denis; KRAUSS, Rosalind; DAMISCH, Hubert. A Conversation with Hubert Damisch. The MIT Press, Vol. 85 (Summer, 1998), pp. 3-17. Disponível em: http://www.jstor.org/stable/779179

CAVALCANTI, Lauro. Abstratos informais. In: Oito décadas de abstração informal: 1940 -2010. Ministério da Cultura, Instituto Casa Roberto Marinho e Museu de Arte Moderna de São Paulo, 2018.

CHAIMOVICH, Felipe. Abstração informal após a vanguarda dos anos 1960. In: Oito décadas de abstração informal: 1940 -2010. Ministério da Cultura, Instituto Casa Roberto Marinho e Museu de Arte Moderna de São Paulo, 2018.

CAMPOS, Augusto de; CAMPOS, Haroldo de; PIGNATARI, Décio. Teoria da poesia concreta: textos críticos e manifestos 1950-1960. São Paulo: Livraria duas cidades, 1975.

CHIARELLI, T. De Anita à academia: para repensar a história da arte no Brasil. In: Novos Estudos - CEBRAP, n.88, p.113-132, 2010 Disponível em: http://www.producao.usp.br/bitstream/handle/BDPI/2755/art_CHIARELLI_De_Anita_a_ academia_para_repensar_a_2010.pdf?sequence=1\&isAllowed=y. Acesso: 23/08/2016.

COCCHIARALLE, Fernando; GEIGER, Anna Bella. Abstracionismo Geométrico e informal: A vanguarda brasileira nos anos 50. Rio de Janeiro: Funarte/Instituto Nacional de Artes Plásticas, 1987.

COUTO, Maria de Fátima Morethy. Mário Pedrosa, Ferreira Gullar e a abstração informal no Brasil. Novos estudos, $n^{\circ} 58,2000$, p. 203-2013.

DAMISCH, Hubert. Remarks on Abstraction. October, 127, Massachusetts Institute of Technology, Winter 2009, pp. 133-154.

DI CAVALCANTI, Emiliano. Realismo e abstracionismo. In: Boletim Satma : Sul América Terrestres Marítimos e Acidentes (Rio de Janeiro, Brasil). No. 23 (1949), 46-51.

ESCOUBAS, Eliane. Investigações fenomenológicas sobre a pintura. KRITERION, Belo Horizonte, $n^{\circ} 112$, Dez/2005, p. 163-173 


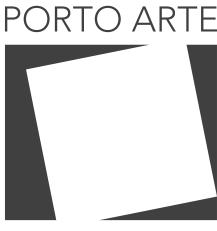

Revista de Artes Visuais v. 25 n. 44 $\mathrm{Jul} / \mathrm{dez} 2020$ e-ISSN: 2179-8001

GULLAR, Ferreira. Teoria do Não Objeto. In: Apologia crítica: suplemento dominical do Jornal do Brasil. Rio de Janeiro: Contra capa, 2015, p. 162.

KANT, Immanuel. Crítica da Faculdade do Juízo. S. C. da Misericórdia do Porto_c_p_a_c - Edições Braille, Porto, 1997.

KUNDERA, Milan. A vida está em outro lugar. São Paulo: Companhia das letras, 2012.

LOPES, A. In: Identidade ou identidades artísticas brasileiras? In: Anais do XXII Colóquio do Comitê Brasileiro de História da Arte, 2002. Disponível em: http://www. cbha.art.br/coloquios/2002/textos/texto08.pdf. Acesso: 20/02/2014.

LYOTARD, Jean-François. 0 pós-moderno explicado às crianças. $2 a$ ed. Lisboa: Dom Quixote, 1993, p. 21-24.

MONTEIRO, Fabiana Della Coletta. Geração 80: sentidos atribuídos e produção de contexto para a arte contemporânea em São Paulo. Revista-Valise, Porto Alegre, v. 7, n. 13, 2017.

Disponível em: https://seer.ufrgs.br/RevistaValise/article/viewFile/66671/43760

MORAIS, Frederico. In:Dan Galeria expõe as pinturas de Luiz Aquila. Org.: Gláucia S. Cohn. Dan Galeria, Rio de Janeiro RJ, 1993, p. 24.

MUSEU NACIONAL DE BELAS ARTES, Rio de Janeiro. Arte em Diálogo: Criação, Produção, Processo... Luiz Aquila. Rio de Janeiro: 2008. v. 7, 28p.

NOVAES, Adauto (org). O Olhar. São Paulo: Companhia das letras, 1988.

NUNES, Fabricio Vaz. Waldemar Cordeiro: da arte concreta ao "popconcreto" Dissertação de mestrado. Universidade de Campinas, SP: [s.n.], 2004.

OLIVEIRA, E. D. G.; FERREIRA, A. W. A construção de um acervo: princípios e estratégias de classificação. Patrimônio e Memória (UNESP), v. 9, 2013, p. 96-112.

OSORIO, Luiz Camillo. Ensaio escrito para exposição Galeria Millan, São Paulo, 2005. Disponível em: http://www.galeriamillan.com.br/artistas/tatiana-blass/textos/ luiz-camillo-osorio Acesso em: 28/1/2019

PEDROSA, Mário. "Prefácio" do catálogo da segunda exposição do grupo Frente, Museu de Arte Moderna do Rio de Janeiro, julho de 1955. In: Cocchiarale, Fernando e Geiger, Anna Bella. Abstracionismo geométrico e informal. A vanguarda brasileira nos anos cinquenta. Rio de Janeiro: Farte, 1987, p. 232.

PUGLIESE, V. Notas sobre um retorno: a abstração moderna e suas condições de possibilidade. In: DONATI, L. A. P. et al. (orgs.). Anais do $27^{\circ}$ Encontro da Associação Nacional de Pesquisadores em Artes Plásticas, setembro de 2018, São Paulo, SP - UNESP. São Paulo: ANPAP: 2019, p. 3856-3870. Disponível em: file:///C:/Users/ verap/Documents/Lattes/2018/2018\%20Anpap\%20Artigo\%20Anais\%2027encontro PUGLIESE_Vera.pdf. Acesso em: 09/12/2019.

REIS, Paulo. Arte de vanguarda no Brasil: os anos 60. Rio de Janeiro: Jorge Zahar Ed., 2006.

VALLIER, Dora. A arte abstrata. São Paulo: Martins Fontes, 1980. 


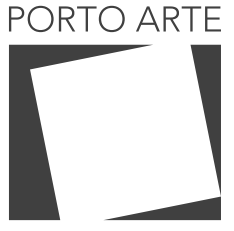

Revista de Artes Visuais

V.25 n. 44 Jul/dez 2020 e-ISSN: 2179-8001

Texto submetido em: 01/dez/2019 Texto aceito em: $24 /$ set $/ 2020$ Texto publicado em: 22/dez/2020

\section{Mayã Gonçalves Fernandes}

Doutoranda em Artes Visuais pela Universidade de Brasília, na linha de pesquisa Teoria e História da Arte (2019) com bolsa CAPES. Mestra em Metafísica, na linha de pesquisa Estética Antiga: Narrativa, Visualidade e Verdade, pela mesma Universidade (2018), com estágio de pesquisa na UBA (Buenos Aires/ARG). Graduada em Filosofia pela Universidade de Brasília (2016). Atualmente investiga a teoria metafísica e abstracionista em Plotino e Kandinsky.

\section{Vera Pugliese}

Professora e pesquisadora em Teoria e Historiografia da Arte do Departamento de Artes Visuais, Instituto de Artes, Universidade de Brasília, atuando também no Programa de Pós-Graduação em Artes Visuais. Doutora e Mestre em Arte/Teoria e História da Arte (UnB), atualmente coordena Projeto de Fomento do CNPq e faz Pós-Doutorado na École des Hautes Études en Sciences Sociales, Paris (bolsista FAP-DF). 